\title{
Challenges and LIS Responses to Digital Literacy in Crisis
}

\section{Michelle Falk}

${ }^{1}$ School of Library and Information Studies, University of Alberta, Email: mkfalk@ualberta.ca

\section{To Cite:}

Falk, M. (2021). Challenges and LIS responses to digital literacy in crisis. [Special Issue]. Pathfinder: A Canadian Journal for Information Science Students and Early Career Professionals, 2(1), 27-33. https://doi/10.29173/pathfinder41

\section{Abstract}

As a result of the COVID-19 pandemic beginning in the Spring of 2020, vulnerable Canadians were left behind by digital exclusion, which was exacerbated by an increased reliance on digital technologies. This paper will provide an overview of the links between digital inclusion, social justice, and the values of the LIS profession. Because of the COVID-19 pandemic crisis, another crisis of digital exclusion has revealed the ways in which digital citizenship and socioeconomic exclusion are fundamentally intertwined. In response, many LIS professionals have overcome extensive closures and reductions in resources to find innovative solutions to this crisis of inequality. This paper will provide just a few examples of these responses from LIS organizations. Indeed, even among overwhelming barriers, LIS professionals have not lost sight of community values and commitment to social justice in challenging times. In unprecedented times, LIS professionals have found innovation to address ongoing social and economic barriers of digital exclusion.

Keywords: digital literacy, digital divide, COVID-19, human rights, social justice, digital inclusion

n compliance with emergency health orders and calls to 'flatten the curve 'in response to the COVID-19 pandemic, which shocked the globe in the Spring of 2020 , there was an increased reliance on distance education, using online tools to facilitate community connections, and mass closures of public institutions. However, this upsurge in technological reliance has worsened the effects of the 'digital divide 'on populations in remote and underserved areas (Stewart, 2020). Libraries have long 
played a role in reducing barriers for vulnerable communities but how can the LIS community work to

provide support for equity-seeking populations left behind by social distancing? Here, this paper will unpack the implications of digital exclusion in perpetuating systemic socio-political barriers, especially in challenging times. In the Canadian context, this paper will begin to explore questions of digital literacy as tied to values of human rights and social justice. This paper concludes by outlining some ways that LIS organizations have found innovative solutions to help vulnerable communities affected by the digital divide in crisis.

\section{Digital Exclusion in Crisis}

Digital inclusion is often conceptualized in terms of physical access, but the cost of online communications and hardware is an often-overwhelming barrier. Long before the COVID-19 pandemic, many experts warned that already disadvantaged communities are further cut off from widespread communication networks and socioeconomic inclusion (Jaeger et al., 2015). According to data from Statistics Canada (2020) the $1.2 \%$ of Canadian households who have no access to the internet, are most commonly found in the lowest quartile of household income. These households are also more likely to use mobile devices such as cell phones to access the internet rather than a computer.

Digital access not only applies to the cost barrier of technology but also internet quality in rural and remote communities. In First Nations communities, only $30 \%$ of households have the recommended internet speed versus $86 \%$ of households Canadawide (Stewart, 2020). Barriers such as these are commonly known as the 'digital divide ' as socio-economically disadvantaged communities are further without equitable access to technologies. These current circumstances are not unique or 'unprecedented, 'as the pandemic has simply exaggerated reality for many individuals living with already few basic resources.

\section{Digital Literacy and Social Justice}

In 1995, Peter Gilster first defined digital literacy as the ability to understand and use information in multiple formats from a wide range of sources when presented via 
computers, and in being able to read with meaning and understand the content (Secker, 2018). Not to be confused with computer literacy, Secker (2018) writes, "Digital literacy recognized the internet as a medium that needed specific literacies to critique information that is provided, to separate truth from fiction and understand how hypertext and non-linear reading allows new meanings to be constructed" (p. 5).

Specifically, with regards to the COVID-19 pandemic, Buchholz et al. (2020) argue that critical digital literacy and citizenship are participatory and intertwined. The pandemic has forced LIS professionals to reconsider what kind of citizenship is required for democratic participation in the "new normal". Even in 2010, a US Federal Communications Commission on the Digital Divide states, "the social function of the Internet has changed dramatically in recent years... what was, until recently, a supplement to other channels of information and communication has become increasingly a basic requirement of social and economic inclusion" (cited in Bach et al., 2013, p. 249). Indeed, research demonstrates that digital exclusion intersects with social and economic exclusion and that socio-economic exclusion is further exacerbated by digital exclusion.

Accordingly, the United Nations International Covenant on Civil and Political Rights draws a clear link between technology and equity, stating: "[Governments] should take all necessary steps to foster the independence of these new media and to ensure access of individuals thereto" (cited in Jaeger et al., 2015, p. 33). Full digital inclusion requires access to the internet to apply the skills of digital literacy. In addition, policymakers at all levels of government have called on libraries to foster civic engagement as an outcome for participants engaging in digital inclusion efforts. The Canadian Library Association's policy on effective school library programs highlights access to quality and current information, stating: "All our young people must have the opportunity to develop the information and media literacy skills they require to reach their fullest potential, to become independent, life-long learners, and to live as active, responsible members of society" (cited in Fogarty, 2016, p. 73).

Clearly, this interconnectedness of LIS values, social inclusion and digital inclusion requires mindful approaches in the practice of social justice, and in translating these theories to practice (Dadlani, 2016). Principles of equality and distributive justice 
are commonly invoked in descriptions of library services to the community with a sense of duty and public morality. As a result, many libraries have embraced a call to action in efforts to lessen the impact of digital exclusion during the COVID-19 pandemic for communities with limited resources. With full library closures due to emergency public health orders, most regular library services were cancelled and resources, such as free community internet access in public libraries, were no longer possible. Despite these challenges, many libraries have found innovative solutions to mitigate the widening digital divide.

\section{Innovation for Digital Inclusion}

Indeed, the most economically vulnerable populations served by public libraries in urban centers are also doubly vulnerable in suffering the worst health outcomes from COVID-19 (Ashworth, 2020). President of the Public Library Association, Ramiro Salazar states, "Shutting down libraries has a tremendous impact on the communities that we serve [...] Until they're closed, sometimes folks don't realize how important libraries are to them" (Ashworth, 2020, para. 6).

Despite these closures, the Calgary Public Library (CPL), for example, has continued to offer an abundance of virtual events and recordings of talks and presentations (Calgary Public Library, 2021b). Specifically, in addressing the question of digital literacy, the public library system developed the Tech Mentors program. This program offers virtual support - through one-on-one meetings with a library volunteer for patrons needing help navigating platforms like Zoom, familiarizing themselves with new software or devices, or getting access to library e-books or other online learning (Calgary Public Library, 2021c). For patrons without internet access, the CPL also offers a Library Hotline - a phone number for community members who need assistance in getting access to book holds, account information, or to connect with other programs such as Tech Mentors. In addition, the Borrow a Computer program lends community members a Chromebook for up to eight weeks, including basic user information and support (Calgary Public Library, 2021a).

School librarians have found similar solutions in addressing the digital divide for students with limited economic resources. In the first wave of the pandemic in Spring 2020, the Seven Oaks School Division in Winnipeg recognized students struggling with 
access to technology adequate to fully engage with online learning and distributed Chromebooks to families in need (Hildebrandt, 2020).

While academic institutions across Canada decided in March 2020 to immediately move all on-campus instruction to an online platform, staff at McGill University Libraries found solutions to maintain student engagement. Including moving one-on-one appointments for reference and IT services to virtual platforms, as well as opening access to e-books and online journals; socially distanced study hubs were made available by appointment for students without adequate space or technology at home (McGill, 2020).

\section{Conclusion}

These are but a few examples of the efforts LIS professionals have made to continue services for vulnerable populations affected by growing digital exclusion. In many ways, the COVID-19 pandemic has been a pressure test on existing systems and has forced a reconceptualization of solutions to already existing challenges. Because of the interconnectedness of values of human rights and social justice and the crucial role of digital literacy for democratic citizenship, LIS professionals can be mindful in meeting these challenges with a commitment to improving outcomes for socio-economically vulnerable populations. In unprecedented times, librarians and information professionals are well-equipped to find innovative solutions for the communities they serve. 


\section{References}

Ashworth, B. (2020, March 25). Covid-19's impact on libraries goes beyond books. Wired. https://www.wired.com/story/covid-19-libraries-impact-goes-beyondbooks/

Bach, A., Shaffer, G., \& Wolfson, T. (2013). Digital human capital: Developing a framework for understanding the economic impact of digital exclusion in lowincome communities. Journal of Information Policy, 3, 247-266. http://doi.org/10.5325/jinfopoli.3.2013.0247

Buchholz, B. A., DeHart, J., \& Moorman, G. (2020). Digital citizenship during a global pandemic: Moving beyond digital literacy. Journal of Adolescent \& Adult Literacy, 64(1), 11-17. http://doi.org/10.1002/jaal.1076

Calgary Public Library. (2021a). Borrow a computer. https://calgarylibrary.ca/yourlibrary/free-services/computers-and-chromebooks/borrow-a-computer/

Calgary Public Library. (2021b). Library updates on COVID-19. https://calgarylibrary.ca/about-the-library/covid-19-updates/

Calgary Public Library. (2021c). Events \& programs. https://calgarylibrary.ca/eventsand-programs/programs/tech-mentors/

Dadlani, P. (2016). Social justice concepts and public libraries: A case study. In U. Gorham, N. Greene Taylor, \& P. T. Jaeger (Eds.), Perspectives on Libraries as Institutions of Human Rights and Social Justice (pp. 15-48). Emerald Group Publishing. http://doi.org/10.1108/S0065-283020160000041002

Fogarty, V. (2016). Libraries and human rights - working together to reach our full potential. In U. Gorham, N. Greene Taylor, \& P. T. Jaeger (Eds.), Perspectives on Libraries as Institutions of Human Rights and Social Justice (pp. 71-90). Emerald Group Publishing. http://doi.org/10.1108/S0065-283020160000041002 Hildebrandt, S. (2020, April 6). Creativity key for school divisions moving forward. Winnipeg Free Press. https://www.winnipegfreepress.com/ourcommunities/times/Creativity-key-for-school-divisions-moving-forward569409281.html

Jaeger, P. T., Greene Taylor, N., \& Gorham, U. (2015). Libraries, human rights, and social justice: Enabling access and promoting inclusion. Rowman \& Littlefield. 
McGill. (2020, August 28). Coming soon! Study hubs at McGill.

https://www.mcgill.ca/library/channels/news/coming-soon-study-hubs-mcgill$\underline{324078}$

Secker, J. (2018). The trouble with terminology: Rehabilitating and rethinking 'digital literacy'. In K. Reedy \& J. Parker (Eds.), Digital Literacy Unpacked (pp. 5-16). Facet Publishing.

Statistics Canada. (2020, April 15). COVID-19 pandemic: School closures and the online preparedness of children. https://www150.statcan.gc.ca/n1/pub/45-280001/2020001/article/00001-eng.htm

Stewart, B. (2020, September 23). How COVID-19 worsens Canada's digital divide. CBC News. https://www.cbc.ca/news/canada/british-columbia/covid-19highlights-urban-rural-digital-divide-1.5734167 